\title{
Pouchitis: Clinical Features, Diagnosis, and Treatment
}

\section{Paolo Gionchetti \\ Carlo Calabrese \\ Silvio Laureti \\ Gilberto Poggioli \\ Fernando Rizzello}

IRCCS Azienda OspedalieroUniversitaria di Bologna, Dipartimento di Scienze Mediche e Chirurgiche (DIMEC), Bologna, Italia
Correspondence: Paolo Gionchetti DIMEC, Via Massarenti 9, Bologna, 40I38, Italia

Email paolo.gionchetti@unibo.it

\begin{abstract}
Procto-colectomy with an ileal pouch anal anastomosis is the procedure of choice for ulcerative colitis patients that require colectomy. Pouchitis is a non-specific inflammation of the ileal reservoir, and the most common, inflammatory and long-term, complication after pouch surgery for ulcerative colitis. The aetiology is still unknown, but many risk factors have been individuated. Pouchitis can be classified based on aetiology, duration, clinical course, and response to antibiotic therapy. Accurate diagnosis and classification is the key factor for an adequate management, and exclusion of secondary causes of pouchitis is pivotal. Most of the patients consistently respond to antibiotic therapy, but management of the subgroup of patients with chronic-antibiotic-resistant-pouchitis is still challenging, being this entity one of the major causes of pouch failure.
\end{abstract}

Keywords: pouchitis, chronic antibiotic refractory pouchitis, classification, diagnosis, management

\section{Introduction}

Procto-colectomy with an ileal pouch anal anastomosis (IPAA) is the procedure of choice for most ulcerative colitis (UC) patients that require colectomy. ${ }^{1}$ Complications are common, and for this reason, ileo-anal pouch surgery should be conducted in high-volume specialist institutions, which have lower complication rate and higher rates of pouch salvage following complications. ${ }^{2}$

Surgical or mechanical complications are caused mainly by factors related to the surgery; these include anastomotic leaks, pelvic sepsis and abscess, pouch sinuses and fistulae, strictures (of the pouch body, pouch inlet, and pouch outlet), afferent limb syndrome and efferent limb syndrome, pouch prolapse. Inflammatory/infectious complications are also frequent and pouchitis, non-specific inflammation of the ileal reservoir, is the most frequent inflammatory complication after an IPAA for $\mathrm{UC}$; reported incidence of pouchitis is largely variable because of differences in nature and duration of the follow-up, occurring in up to $50 \%$ of the patients 10 years after IPAA in large series from major referral centers. ${ }^{3-13}$ Most patients who develop acute pouchitis do so within the first year, but some may suffer their first attack some years following surgery. ${ }^{12}$

The aetiology of pouchitis is still unknown, and is likely to be multifactorial; it is supposed that a close interaction between the host immune response and the microbiota play a substantial role. ${ }^{14}$

There is evidence that the intestinal microbial community plays an important role in maintaining pouch health or driving pouch inflammation. ${ }^{15}$ In support of this 
hypothesis, pouchitis only occurs after restoration of the fecal stream through the pouch. ${ }^{16,17}$ In addition, a dysbiosis in pouchitis has been documented, ${ }^{18}$ and several genes associated with the innate immune response and microbial sensing and recognition have been associated with an increased risk for pouchitis, including the NOD2/ CARD15 gene, ${ }^{19,20}$ IL-1 receptor antagonist gene ${ }^{21}$ and Toll-like receptor genes. ${ }^{22}$

Reported risk factors for pouchitis include, being a non-smoker extensive $\mathrm{UC}^{23}{ }^{23}$ backwash ileitis, ${ }^{24}$ extraintestinal manifestations (EIMs) especially primary sclerosing cholangitis (PSC), ${ }^{9,25,26}$ regular use of non-steroidal anti-inflammatory drugs (NSAIDs), ${ }^{27}$ and concomitant autoimmune disorders. $^{28,29}$

Pouch configuration with two $(\mathrm{J})$, three $(\mathrm{S})$, or four $(\mathrm{W})$ loops of small intestine has been performed, and the $\mathrm{J}$ pouch has become the most commonly used one, being accepted as the preferred technique due to ease of construction and efficiency of evacuation. ${ }^{30}$

\section{Clinical Features}

This syndrome is clinically characterized by variable symptoms, including increased stool frequency and fluidity, rectal bleeding, abdominal cramping, urgency, tenesmus, nighttime faecal seepage. ${ }^{31,32}$ Rectal bleeding, low-grade fever, EIMs and incontinence may also occur. These symptoms, however, are not specific of pouchitis, and may be caused by other conditions such as cuffitis, ${ }^{33}$ Crohn's disease (CD) of the pouch ${ }^{34-36}$ and irritable pouch syndrome. ${ }^{37}$

Pouchitis can be classified based on disease duration and clinical course, and response to medical therapy. Pouchitis may then be divided into acute $(\leq 4$ weeks) or chronic ( $>4$ weeks), depending on the symptom duration. Pouchitis recurs in more than $50 \%$ patients; patients with recurrent pouchitis can broadly be grouped into three categories: infrequent ( $<3$ episodes/yr), with a relapsing course (1-3 episodes/yr) or with a continuous course. Pouchitis may further be termed, based on response to antibiotic monotherapy, in antibiotic-responsive, antibiotic-dependent (ie, requiring ongoing antibiotic therapy to keep disease in remission), and antibiotic-refractory (ie, not responding to a standard course of antibiotic therapy). $^{38}$

These classifications are obviously interrelated, and combination of the above terms and characteristics is used to define particular type of pouchitis, such as chronic antibiotic-refractory pouchitis (CARP), in which are included patients who do not respond to standard 2-week, antibiotic monotherapy for pouchitis, which management is very difficult. ${ }^{5,38}$

In $20-25 \%$ of the cases, refractory pouchitis may be due to other conditions, and before a diagnosis of CARP is done, these conditions should be ruled out. ${ }^{39}$

Secondary causes may include inflammatory pouch disorders (eg, CD, cuffitis, pouch anastomotic sinus, pouch fistula), infection with specific pathogens (eg, cytomegalovirus, Clostridioides difficile); vascular or mechanical factors (such as ischaemia, prolapse and pouch obstruction), nonsteroidal anti-inflammatory drug use, autoimmuneassociated (eg, IgG4-associated, PSC-associated). ${ }^{40}$

Ischemia is frequent, and it is characterized by asymmetric inflammation of the pouch with a clear limit with the non-inflamed pouch mucosa. ${ }^{41}$

Risk factors include male gender and obesity; ischemic pouchitis can be very challenging to treat and most of the patients do not respond to antibiotic therapy. Patients may determine fibrotic or long stenosis and patients may develop pouch failure, leading to pouch excision. ${ }^{40,41}$

Diagnosis CD of the pouch can occur at a distance from surgery with an increasing cumulative incidence over time. A recent study reported that cumulative incidence was $7.5 \%$ at 5 years postoperatively and gradually increased to $17.7 \%$ and $33.0 \%$ at 10 and 20 years. ${ }^{42} \mathrm{CD}$ of the pouch can be diagnosed after IPAA intentionally performed in selected group of patients with $\mathrm{CD}$, can be inadvertently found in colectomy specimens of patients with preoperative diagnosis of $\mathrm{UC}$, in patients labelled as indeterminate colitis, and, more frequently, de novo CD can occur months or years after pouch surgery. ${ }^{35}$

In the presence of perianal disease, a diagnosis of $C D$ should be considered if fistulae or abscess develop greater than 6-12 months after IPAA, develop in area outside pouch-anal anastomosis or in case of concurrent small bowel disease.

Clostridioides difficile infection (CDI) is more common cause of refractory pouchitis than cytomegalovirus (CMV) infection reaching $11 \% ;{ }^{43} \mathrm{CDI}$ in patients who underwent pouch surgery is very often refractory or recurrent. The occurrence of post-surgical mechanical complications was a risk factor for refractory or recurrent CDI of the ileal pouch. ${ }^{44}$

Use of NSAIDs after pouch surgery postoperatively, is associated with acute and chronic pouchitis. Furthermore, patients on regular NSAIDs and pouch-related disorders benefit from complete discontinuation of these drugs. ${ }^{27}$ 
A subgroup of patients with pouchitis has concurrent immune-mediated conditions including primary sclerosing cholangitis (PSC), seropositivity for immunoglobulin G4 (IgG4) and infiltration of IgG4-expressing plasma cells in the pouch mucosa. ${ }^{45}$

Once secondary pouchitis is ruled-out a diagnosis of CARP is made.

\section{Diagnosis}

Patients with pouchitis may have a variable clinical presentation; pouchitis should be suspected in patients with increased stool frequency and liquidity, urgency, abdominal cramps, night-time fecal seepage, pelvic pressure, tenesmus, or incontinence. Since these symptoms are not specific to pouchitis, it is also required the exclusion of other diagnoses by history, laboratory evaluation, endoscopy and biopsy with histology and, in some cases, abdominal/pelvic imaging. Accurate diagnosis and classification are important for appropriate management. The diagnosis of pouchitis should not be based only on symptoms assessment; endoscopic evaluation with biopsies of the mucosa of the pouch body and of the afferent limb is the most important tool for the diagnosis and differential diagnosis. ${ }^{38,45}$ Pouchoscopy and pouch mucosal biopsy should be always done when symptoms compatible with pouchitis are present. ${ }^{46-47} \mathrm{~A}$ stricture may be present in patient with IPAA, and therefore a pediatric colonscope or a gastroscope is preferred for endoscopic evaluation. During pouchoscopy the afferent limb, inlet, tip of the J, proximal and distal pouch, anastomosis, rectal cuff, anal canal, and perianal area should be evaluated. Endoscopic findings are not specific and include diffuse erythema, which may be patchy, oedema, granularity, friability, spontaneous or contact bleeding, loss of vascular pattern, mucous exudates, haemorrhage, erosions and ulceration. Erosions and/or ulcers along the staple line should not be considered as diagnostic tool of pouchitis. ${ }^{5,46}$ Inflammation of the rectal cuff is also frequent, and cuff biopsies are helpful to diagnose cuffitis, which is the inflammation of the retained rectal mucosa (columnar cuff) above the anal transitional zone (ATZ) after stapled anastomosis. Usually, patients have no symptoms, which may be due to complications (such as stenosis); anal irritation/discomfort, pouchitis-like symptoms, extraintestinal manifestations, rectal bleeding and tenesmus are the most frequent. ${ }^{33}$

There are several diagnostic indices to assess inflammation of the pouch. The most widely used is the 18-point pouchitis disease activity index (PDAI), which include symptom ( $0-6$ points), endoscopy ( $0-6$ points), and histology ( $0-6$ points) subscores. A total PDAI score of $\geq 7$ points is considered diagnostic for pouchitis, ${ }^{47}$ but this score is not specific and irritable pouch syndrome or other inflammatory disorders of the pouch (eg, cuffitis, $\mathrm{CD}$ of the pouch) can also elevate the PDAI. ${ }^{48}$ A modified PDAI (mPDAI), which excludes histology score, has been proposed, with similar diagnostic accuracy when compared with the PDAI for the diagnosis of pouchitis with a score of $\geq 5$. ${ }^{49}$

Recently, 12 panelists used a modified RAND appropriateness methodology to rate the appropriateness of items evaluating endoscopic pouchitis disease activity. Four central readers then evaluated 50 pouchoscopy videos in triplicate, in random order. Intra- and inter-rater reliability for each item was assessed. Substantial reliability was observed only for the endoscopic items of ulceration and ulcerated surface in the pouch body. ${ }^{50}$

In a study including consecutive asymptomatic patients after pouch surgery for UC, undergoing surveillance pouchoscopy, "incidental" abnormal endoscopic and/or histologic findings were common, suggesting the utility of endoscopic surveillance. ${ }^{51}$ More recently, a study showed that ulcers and/or erosions were observed in about $20 \%$ of asymptomatic patients and were associated with an increased risk of acute pouchitis. ${ }^{52}$

In a retrospective paper, prepouch ileitis (PI) was present in 33/546 (6\%) and in 57/1286 (4.4\%) patients and most of these had concurrent pouchitis, with endoscopic findings characterized by erosions, ulcerations, erythema, friability. Of the patients with PI about $20 \%$ received no specific treatment, one-fourth responded to antibiotics, $50 \%$ required escalation in therapy to steroids/immunomodulators or anti-TNF $\alpha$, with $<20 \%$ of pouch failure.

Immunosuppressive/biological treatment was required more frequently in patients with PI than those with pouchitis alone. $^{53}$

More recently, overall incidence of PI among 1286 patients was reported to be of $4.4 \%$; symptoms included increased frequency (26.4\%), outlet obstruction (21\%), and bleeding (15.8\%). Afferent limb stenosis affected $49.1 \%$ of the patients. CD, indeterminate colitis, and stenosis with outlet obstruction are risk factors for failure of treatment after diagnosis of PI. ${ }^{54}$

Biopsies should be taken from the mucosa of the pouch body and from the mucosa of the afferent limb above the pouch, and not along the stapled line. 
Histological findings of pouchitis which include acute inflammation with polymorphonuclear leukocyte infiltration, crypt abscesses and ulceration, in association with a chronic inflammatory infiltrate, are also non-specific ${ }^{47}$; moreover, there might be discrepancy between endoscopic and histologic findings in pouchitis. ${ }^{54,55}$ Although histology has a limited role in grading the degree of pouch inflammation, it can provide useful information on some specific pathogenetically relevant features, such as the presence of granulomas, viral inclusion bodies (characteristic of CMV), dysplasia or cancer, ischaemia or prolapse. We suggest to perform biopsies at every pouch endoscopy performed.

\section{Laboratory Findings}

Patients may have iron deficiency anemia due to insufficient iron absorption or utilization or blood loss. Low serum vitamin $\mathrm{D}$ levels may be also reported by patients with ileal pouches, even in the absence of concurrent mucosal inflammation. Patients with concurrent primary sclerosing cholangitis or IgG4-associated cholangiopathy may have an elevation of alkaline phosphatase and/or bilirubin. Antinuclear antibody, antimicrosomal antibodies, and IgG4 can also be assessed to rule out primary sclerosing cholangitis and IgG4 cholangitis. ${ }^{38,39,45}$

Stool studies should include stool $C$. difficile toxin. For patients with systemic symptoms, such as fever, chills, night sweats, weight loss, and leukocytosis, stool cultures for other intestinal pathogens (eg, Salmonella, Shigella, Campylobacter, Yersinia) and specific testing for E. coli O157:H7 should be performed.

In patients with antibiotic-refractory or antibioticdependent pouchitis, additional tests may be useful to rule out other etiologies and identify pouch-related complications (eg, CD, stricture, abscess, sinus, or fistula). When CD of the pouch is suspected, assessment of laboratory findings, together with clinical, endoscopic, histologic and imaging (ultrasound, MRI, CT scan) evaluation, as well as examination by a colorectal surgeon in case of suspected perianal disease (including anoscopy, anal ultrasound, and MRI) is advised. ${ }^{38,39,45}$

Surgery-associated complications, such as pouch anastomotic leaks or sinus, pelvic abscess, and pouch ischemia, should be suspected in patients who experience symptoms suggestive of pouchitis rapidly after pouch construction and ileostomy closure, and do not respond to the antibiotic therapy; this condition can be differentiated from pouchitis based on history, pouchoscopy with biopsy, and imaging (water-soluble contrast enema and $\mathrm{MRI} / \mathrm{CT}$ enterography).

If patients have, or if it is suspected, a concurrent PSC, abdominal imaging studies, such as ultrasonography or magnetic resonance cholangiopancreatography should be performed. ${ }^{38,39,45}$

Pouch failure is defined as the need for permanent diversion, with or without pouch excision. The reported cumulative frequency ranged from $4 \%$ to $10 \%$. ${ }^{4,56,57}$

The most common causes are pelvic sepsis, CARP, CD of the pouch and pouch fistula or sinus.

\section{Management of Pouchitis}

The disease course of pouchitis is different among different patients. About one-third of patients may have only a single episode of acute pouchitis. ${ }^{26}$ However, two-thirds of patients will have a recurrent pouchitis, of which approximately one-third will develop CARP. ${ }^{58}$

\section{Treatment of Acute Pouchitis}

Accurate diagnosis and classification are important for appropriate management. Treatment of pouchitis is largely empiric and only few small placebo-controlled trials have been conducted.

The awareness of the crucial importance that fecal stasis and the bacterial overgrowth in the pathogenesis of acute pouchitis has led the clinicians to treat patients with antibiotics, which have become the mainstay of treatment, in the absence of controlled trials. Usually, metronidazole and ciprofloxacin are the most common initial therapy, with good response in the majority of cases, although the optimum modality of treatment is not clearly defined. $5,31,38$.

Metronidazole and ciprofloxacin have been compared in a small randomized trial; seven patients received ciprofloxacin $1 \mathrm{~g} /$ day and nine patients metronidazole $20 \mathrm{mg} / \mathrm{kg} /$ day for a period of 2 weeks. Ciprofloxacin lowered the PDAI score from $10.1 \pm 2.3$ to $3.3 \pm 1.7(\mathrm{p}=0.0001)$, whereas metronidazole reduced the PDAI score from $9.7 \pm 2.3$ to 5.8 $\pm 1.7(\mathrm{p}=0.0002)$. There was a significantly greater benefit with ciprofloxacin than with metronidazole in terms of the total PDAI $(p=0.002)$, symptom score $(p=0.03)$ and endoscopic score $(p=0.03)$, as well as fewer adverse events (33\% of metronidazole-treated patients reported side effects, but none on ciprofloxacin). ${ }^{59}$ A small controlled trial of $2 \mathrm{mg}$ budesonide enemas showed efficacy similar to oral metronidazole $500 \mathrm{mg}$ b.d.s. However, $57 \%$ of metronidazole-treated patients had adverse events vs only 
$25 \%$ in the budesonide group. ${ }^{60}$ Neither rifaximin nor Lactobacillus plantarum GG were more effective than placebo in two controlled trials. ${ }^{61,62}$

In a non-randomised, non-controlled, open-label trial, a highly concentrated probiotic preparation (De Simone formulation) was shown to be effective in the treatment of mildly active pouchitis when used at very high-dose. ${ }^{63}$

\section{Treatment of Secondary Pouchitis}

The most important approach is the elimination of causing factor, such as NSAID use, eradication of infection, correction of mechanical complications.

CDI is a common cause of secondary pouchitis. The treatment of CDI in IPAA is largely empiric, in fact there are no published prospective trials. Oral vancomycin should be considered first line in the management of pouch CDI. Recommended dose of oral vancomycin is 500-1000mg/day for 2-4 weeks.

Patients with concurrent inflammatory or mechanical conditions of the pouch, such as pouch outlet stricture, cuffitis and $\mathrm{CD}$ of the pouch, should be treated either with endoscopic dilation, or topical anti-inflammatory agents, immunomodulators and/or biological therapy.

Ischemia may determine fibrotic or long stenosis and patients may develop pouch failure, leading to pouch excision.

\section{Primary and Secondary Prophylaxis}

The probiotic preparation "De Simone Formulation" has been shown to prevent pouchitis onset within the first year after surgery in a randomised, double-blind, placebo-controlled study. Forty consecutive patients who underwent ileal pouch-anal anastomosis for ulcerative colitis were randomized to receive either the probiotic formulation ( 2 packets containing 450 billion bacteria of different 8 strains each/day) $(\mathrm{n}=20)$ or an identical placebo $(n=20)$ immediately after ileostomy closure for 1 year. The patients were assessed clinically, endoscopically, and histologically after $1,3,6,9$, and 12 months. Two of the 20 patients $(10 \%)$ treated with the probiotic formulation had an episode of acute pouchitis compared with 8 of the 20 patients $(40 \%)$ treated with placebo ( $\log$ rank test, $\mathrm{z}=2.273 ; \mathrm{P}<0.05$ ), and experienced a significant improvement in their quality of life. ${ }^{64}$

In an open, retrospective study, Lactobacillus rhamnosus GG seemed to have some efficacy for delaying the first episode of pouchitis. ${ }^{65}$
Tinidazole showed some benefit in small, randomized, placebo-controlled trial, published only as an abstract, in prevention of onset of pouchitis; $81 \%$ (21/26) of tinidazole patients had no episodes of pouchitis compared to $58 \%$ (7/ 12) of placebo patients during the first year after ileostomy closure. $^{66}$

Patients with antibiotic-responsive pouchitis could develop frequent relapses and require maintenance therapy. Two double-blind, randomized, placebo-controlled studies have shown the efficacy of "De Simone Formulation" to maintain remission in patients with chronic pouchitis who obtained remission after 1 month of therapy with antibiotic combination. ${ }^{67,68,69}$

In the first study 40 patients who went into clinical and endoscopic remission after 1 month of combined antibiotic treatment (rifaximin $2 \mathrm{~g} /$ day + ciprofloxacin $1 \mathrm{~g} /$ day) were randomized to receive either the highly concentrated probiotic preparation, 4 packets/day $\left(18 \times 10^{11}\right.$ bacteria/day), or placebo for 9 months. All 20 patients who received placebo relapsed, while $17 / 20$ patients $(85 \%)$ treated with the probiotic formulation remained in clinical and endoscopic remission at the end of the study. Interestingly, all 17 patients relapsed within 4 months of stopping probiotics. In the second study, 36 patients with chronic, refractory pouchitis who achieved remission $(\mathrm{PDAI}=0)$ after 1 month of combined antibiotic treatment (metronidazole + ciprofloxacin) received 4 packets a day of "De Simone formulation" or placebo for 1 year. Remission rates at 1 year were $85 \%$ in the probiotic group and $6 \%$ in the placebo group $(\mathrm{p}<0.001)$.

Alternative therapeutic options for patients with antibiotic-dependent pouchitis who do not respond to probiotic maintenance therapy include long-term, low-dose antibiotic treatment. However, long-term use of antibiotic may be associated with antibiotic-resistance, adverse effects and possible opportunistic infection. In an observational study, chronic antibiotic-dependent pouchitis had been maintained on antibiotics continuously for at least 1 year; remission was achieved in $21 \%$ of the patients over a median follow-up of 102 (range 9-125). The most common antibiotics used were ciprofloxacin $(30 \%)$, metronidazole $(19 \%)$ or a combination of both $(11 \%)$. The other antibiotics included colistin, rifaximin and cephalexin. We suggest in some patients the use of antibiotic for 1 week per month alternating antibiotics. Pouch failure occurred in $18 \%$, side effects of long-term antibiotic use occurred in $28 \%$ of the patients, with resistance to antibiotics from at 
least one stool sample occurring in $78 \%$ patients. ${ }^{69}$ Redopouch can be attempted in some cases. ${ }^{70}$

\section{Treatment of CARP}

Treatment of CARP is challenging and this form of pouchitis is one of the most common causes of pouch failure.

A combination of two antibiotics can be effective, such as ciprofloxacin ( $1 \mathrm{~g}$ per day) with either rifaximin (2 $\mathrm{g}$ per day) metronidazole (1 g per day) or tinidazole (1$1.5 \mathrm{~g}$ per day) for 4 weeks. $^{71-75}$

Oral budesonide for 8 weeks determined $75 \%$ of remission; ${ }^{76}$ oral beclomethasone dipropionate ${ }^{77}$ and topical tacrolimus are effective alternatives. ${ }^{77}$

In case of failure in inducing remission, systemic corticosteroids, immunosuppressants and anti-TNF drugs including infliximab and adalimumab can be used.

A recent meta-analysis evaluating the efficacy of antiTNF therapy on chronic refractory pouchitis have shown that the rates of short-term and long-term clinical remission were $0.50(95 \%$ CI $[0.37-0.63] ; \mathrm{I} 2=0.57)$ and 0.52 (95\% CI [0.39-0.65]; I2 = 0.59), respectively. ${ }^{78}$

More recently, also vedolizumab and ustekinumab have been tested in the treatment of CARP.

Efficacy of vedolizumab was evaluated in a retrospective, multicenter cohort study at five academic referral centers in the United States. Eighty-three patients were treated with vedolizumab and the median follow-up was 1.3 years; the proportion of patients that achieved at least a clinical response was $71.1 \%$, with $19.3 \%$ achieving clinical remission; the rate of endoscopic response and mucosal healing was $54.1 \%$ and $17.6 \%$, respectively. Patients who developed pouchitis symptoms less than 1 year after undergoing IPAA were less likely to respond to vedolizumab. ${ }^{79-81}$

In a single-center, retrospective study, patients with CARP who received vedolizumab were evaluated; of 19 patients treated $10(53 \%)$ had anti-TNFs after pouch surgery. Six $(32 \%)$ patients had improvement in the mPDAI symptom subscores and 14 (74\%) had improvement in both endoscopic and total mPDAI scores, and four (21\%) required surgery for $\mathrm{CARP}{ }^{81}$

In a retrospective single-center study, 24 patients with CARP, received ustekinumab with standard CD dosing. Twelve patients $(50 \%)$ had a clinical response with the median number of bowel movements within 24 $\mathrm{h}$ decreasing from 8 (IQR, 5-12) to 6 (IQR, 5-8) $\mathrm{P}=$ 0.002 . Pouchoscopy was available only in 13 patients, and the median endoscopic subscore of the PDAI decreased from 5 (IQR, 3-6) to 4 (IQR, 2-5), $\mathrm{P}=0.016 .{ }^{82}$

\section{Conclusions}

Pouch surgery is a complex surgery and should be performed by experienced surgeon in a high-volume center. Pouchitis is the most common long-term complication of IPAA, and is a syndrome including many different diseases. Etiology in unknown but dysbiosis has a key role in the disease initiation and development. Risk factors include NOD2/CARD15 mutation, being a non-smoker, extensive UC, backwash ileitis, extraintestinal manifestations (EIM) especially PSC, regular use of NSAIDs, and concomitant autoimmune disorders. Diagnosis and classification should be accurate for appropriate management; pouch endoscopy is the most effective technique for diagnosis and differential diagnosis. Most of the patients with pouchitis respond rapidly to antibiotic therapy, but management of CARP is still challenging, being one of the most frequent causes of pouch failure. Secondary causes should be ruled out before a diagnosis of CARP is made, and this can improve prognosis.

\section{Author Contributions}

All authors made substantial contributions to conception and design, acquisition of data, or analysis and interpretation of data; took part in drafting the article or revising it critically for important intellectual content; agreed to submit to the current journal; gave final approval of the version to be published; and agree to be accountable for all aspects of the work.

\section{Disclosure}

Prof. Dr Paolo Gionchetti reported personal fees from Takeda, Janssen, Ferring, Alfa-Sigma, Celgene, Arena, Gilead, Abbvie, Biogen, Celltrion, BMS, Chiesi, Sofar, Pfizer, Sandoz, outside the submitted work. The authors report no other conflicts of interest in this work.

\section{References}

1. Fazio VW, Ziv Y, Church JM, et al. Ileal pouch-anal anastomoses complications and function in 1005 patients. Ann Surg. 1995;222:120-127. doi:10.1097/00000658-199508000-00003

2. Gionchetti P, Dignass A, Danese S, et al. 3rd European evidence-based consensus on the diagnosis and management of crohn's disease 2016: part 2: surgical management and special situations. J Crohns Colitis. 2017;11(2):135-149. doi:10.1093/ecco-jcc/jjw169

3. Li Y, Shen B. Evaluating Pouch Problems. Gastroenterol Clin N Am. 2012;41:355-378. doi:10.1016/j.gtc.2012.01.013

4. Sandborn WJ. Pouchitis following ileal pouch-anal anastomosis: definition, pathogenesis, and treatment. Gastroenterology. 1994;107:1856-1860. doi:10.1016/0016-5085(94)90832-х 
5. Magro F, Gionchetti P, Eliakim R, et al. Third European evidence-based consensus on diagnosis and management of ulcerative colitis. part 1: definitions, diagnosis, extra-intestinal manifestations, pregnancy, cancer surveillance, surgery, and ileo-anal pouch disorders. J Crohn's Colitis. 2017:649-670. doi:10.1093/ecco-jcc/jjx008

6. Magro F, Lopes S, Rodrigues S, Azevedo I. How to manage pouchitis in ulcerative colitis? Curr Drug Targets. 2011;12:1454-1461. doi:10.2174/1389450011796818144

7. Hurst RD, Molinari M, Chung TP, Rubin M, Michelassi F. Prospective study of the incidence, timing and treatment of pouchitis in 104 consecutive patients after restorative proctocolectomy. Arch Surg. 1996;131:497-500. doi:10.1001/archsurg.1996.01430170043007

8. Meagher AP, Farouk R, Dozois RR, Kelly KA, Pemberton JH. J ileal pouch-anal anastomosis for chronic ulcerative colitis: complications and long-term outcome in 1310 patients. $\mathrm{Br} J$ Surg. 1998;85:800-803. doi:10.1046/j.1365.2168.1998.00589.x

9. Simchuk EJ, Thirlby RC. Risk factors and true incidence of pouchitis in patients after ileal pouch-anal anastomoses. World J Surg. 2000;24:851-856. doi:10.1007/s002680010136

10. Penna C, Dozois R, Tremaine W, et al. Pouchitis after ileal pouch-anal anastomosis for ulcerative colitis occurs with increased frequency in patients with associated primary sclerosing cholangitis. Gut. 1996;38:234-239. doi:10.1136/gut.38.2.234

11. Shen B, Fazio VW, Remzi FH, et al. Comprehensive evaluation of inflammatory and noninflammatory sequelae of ileal pouch-anal anastomoses. Am J Gastroenterol. 2005;100:93-101. doi:10.1111/ j.1572-0241.2005.40778.x

12. Stahlberg D, Gullberg K, Liljeqvist L, Hellers G, Lofberg R. Pouchitis following pelvic pouch operation for ulcerative colitis. Incidence, cumulative risk, and risk factors. Dis Colon Rectum. 1996;39:1012-1018. doi:10.1007/BF02054692

13. Svaninger G, Nordgren S, Oresland T, Hulten L. Incidence and characteristics of pouchitis in the Kock continent ileostomy and the pelvic pouch. Scand J Gastroenterol. 1993;28:695-700. doi:10.3109/ 00365529309098275

14. Landy J, Al-Hassi HO, McLaughlin SD, et al. Etiology of pouchitis. Inflamm Bowel Dis. 2012;18:1146-1155. doi:10.1002/ibd.21911

15. Batista D, Raffals L. Role of intestinal bacteria in the pathogenesis of pouchitis. Inflamm Bowel Dis. 2014;20:1481-1486. doi:10.1097/ MIB.0000000000000055

16. Nicholls RJ, Belliveau P, Neill M, Wilks M, Tabaqchali S. Restorative proctocolectomy with ileal reservoir: a pathophysiological assessment. Gut. 1981;22:462-468. doi:10.1136/gut.22.6.462

17. Santavirta J, Mattila J, Kokki M, Matikainen M. Mucosal morphology and fecal bacteriology after ileoanal anastomosis. Int J Colorectal Dis. 1991;6:38-41. doi:10.1007/BF00703959

18. Ruseler-van Embden JG, Schouten WR, van Lieshout LM. Pouchitis: result of microbial imbalance? Gut. 1994;35:658-664. doi:10.1136/ gut.35.5.658

19. Meier CB, Hegazi RA, Aisenberg J, et al. Innate immune receptor genetic polymorphisms in pouchitis: is CARD15 a susceptibility factor? Inflamm Bowel Dis. 2005;11(11):965-971. doi:10.1097/01. mib.0000186407.25694.cf

20. Tyler AD, Milgrom R, Stempak JM, et al. The NOD2insC polymorphismis associated with worse outcome following ileal pouch-anal anastomosis for ulcerative colitis. Gut. 2013;62:1433. doi:10.1136/ gutjnl-2011-301957

21. Carter MJ, Di Giovine FS, Cox A, et al. The interleukin 1 receptor antagonist gene allele 2 as a predictor of pouchitis following colectomy and IPAA in ulcerative colitis. Gastroenterology. 2001;121:805-811. doi:10.1053/gast.2001.28017

22. Lammers KM, Ouburg S, Morre SA, et al. Combined carriership of TLR9-1237C and CD14-260T alleles enhances the risk of developing chronic relapsing pouchitis. World $J$ Gastroenterol. 2005;11:7323-7329. doi:10.3748/wjg.v11.i46.7323
23. Merrett MN, Mortensen N, Kettlewell M, Jewell DO. Smoking may prevent pouchitis in patients with restorative proctocolectomy for ulcerative colitis. Gut. 1996;38:362-364. doi:10.1136/gut.38.3.362

24. Schmidt CM, Lazenby AJ, Hendrickson RJ, Sitzmann JV. Preoperative terminal ileal and colonic resection histopathology predicts risk of pouchitis in patients after ileoanal pull-through procedure. Ann Surg. 1998;227:654-662. doi:10.1097/00000658199805000-00006

25. Shepherd NA, Hulten L, Tytgat GN, et al. Pouchitis. Int J Colorectal Dis. 1989;4:205-229. doi:10.1007/BF01644986

26. Lohmuller JL, Pemberton JH, Dozois RR, Ilstrup D, van Heerden J. Pouchitis and extraintestinal manifestations of inflammatory bowel disease after ileal pouch-anal anastomosis. Ann Surg. 1990;211:622-627.

27. Shen B, Fazio VW, Remzi FH, et al. Effect of withdrawal of nonsteroidal anti-inflammatory drug use on ileal pouch disorders. Dig Dis Sci. 2007;52:3321-3328. doi:10.1007/s10620-006-9710-3

28. Achkar JP, Al-Haddad M, Lashner B, et al. Differentiating risk factors for acute and chronic pouchitis. Clin Gastroenterol Hepatol. 2005;3:60-66. doi:10.1016/s1542-3565(04)00604-4

29. Shen B, Remzi FH, Nutter B, et al. Association between immune-associated disorders and adverse outcomes of ileal pouch-anal anastomosis. Am J Gastroenterol. 2009;104:655-664. doi:10.1038/ajg.2008.76

30. Sagar PM, Taylor BA. Pelvic ileal reservoirs: the options. Br J Surg. 1994;81:325-332. doi:10.1002/bjs.1800810304

31. Pardi DS, D’Haens G, Shen B, Campbell S, Gionchetti P. Clinical guidelines for the management of pouchitis. Inflamm Bowel Dis. 2009;15:1424-1431. doi:10.1002/ibd.21039

32. Pardi DS, Sandborn WJ. Systematic review: the management of pouchitis. Aliment Pharmacol Ther. 2006;23:1087-1096. doi:10.1111/j.1365-2036.2006.02884.x

33. Shen B, Lashner BA, Bennett AE, et al. Treatment of rectal cuff inflammation (cuffitis) in patients with ulcerative colitis following restorative proctocolectomy and ileal pouch-anal anastomosis. Am J Gastroenterol. 2004;99:1527-1531. doi:10.1111/j.1572-0241.2004.30518.x

34. Shen B, Fazio VW, Remzi FH, et al. Clinical features and quality of life in patients with different phenotypes of Crohn's disease of the ileal pouch. Dis Colon Rectum. 2007;50:1450-1459. doi:10.1007/ s10350-007-0284-8

35. Shen B. Crohn's disease of the pouch: reality, diagnosis, and management. Inflamm Bowel Dis. 2009;15:284-294. doi:10.1002/ibd.20661

36. Lightner AL, Fletcher JG, Pemberton JH, Mathis KL, Raffals LE, Smyrk T. Crohn's Disease of the Pouch: a true diagnosis or an oversubscribed diagnosis of exclusion? Dis Colon Rectum. 2017;60 (11):1201-1208. doi:10.1097/DCR.0000000000000918

37. Shen B, Achkar JP, Lashner BA, et al. Irritable pouch syndrome: a new category of diagnosis for symptomatic patients with ileal pouch-anal anastomosis. Am J Gastroenterol. 2002;97:972-977. doi:10.1111/j.1572-0241.2002.05617.x

38. Shen B. Acute and chronic pouchitis - pathogenesis, diagnosis and treatment. Nat Rev Gastroenterol Hepatol. 2012;9:323-333. doi:10.1038/nrgastro.2012.58

39. Shen B. Pouchitis: what Every Gastroenterologist Needs to Know. Clin Gastroenterol Hepatol. 2013;11:1538-1549. doi:10.1016/j. cgh.2013.03.033

40. Navaneethan U, Shen B. Secondary Pouchitis: those With Identifiable Etiopathogenetic or Triggering Factors. Am J Gastroenterol. 2010;105:51-64. doi:10.1038/ajg.2009.530

41. Shen B, Plesec TP, Remer E, et al. Asymmetric endoscopic inflammation of the ileal pouch: a sign of ischemic pouchitis? Inflamm Bowel Dis. 2012;16:836-846. doi:10.1002/ibd.21129

42. Hercun J, Côté-Daigneault J, Lahaie RG, Richard C, Wassef R, Poitras P. Crohn's Disease after Proctocolectomy and Ileal Pouch Anal Anastomosis for Ulcerative Colitis. Dis Colon Rectum Dec. 2020. doi:10.1097/DCR.0000000000001721 
43. Li Y, Qian J, Queener E, Shen B. Risk factors and outcome of PCR-detected Clostridium difficile infection in ileal pouch patients. Inflamm Bowel Dis. 2013;19:397-403. doi:10.1097/ MIB.0b013e318280fcb9

44. Seril DN, Ashburn JH, Lian L, Shen B. Risk Factors and Management of Refractory or Recurrent Clostridium difficile Infection in Ileal Pouch Patients. Inflamm Bowel Dis. 2014;20:378-388. doi:10.1097/MIB.0000000000000205

45. Ardalan ZS, Sparrow MP. A Personalized Approach to Managing Patients With an IlealPouch-Anal Anastomosis. Front Med. 2020;337:1-20. doi:10.3389/fmed.2019.00337

46. Shen B, Achkar JP, Lashner BA, et al. Endoscopic and histologic evaluation together with symptom assessment are required to diagnose pouchitis. Gastroenterology. 2001;121:261-267. doi:10.1053/ gast.2001.26290

47. Moskowitz RL, Shepherd NA, Nicholls RJ. An assessment of inflammation in the reservoir after restorative proctocolectomy with ileoanal ileal reservoir. Int $J$ Colorectal Dis. 1986;1:167-174. doi:10.1007/BF01648445

48. Mahadevan U, Sandborn WJ. Diagnosis and management of pouchitis. Gastroenterology. 2003;124:1636-1650. doi:10.1016/ s0016-5085(03)00325-1

49. Shen B, Achkar JP, Connor JT, et al. Modified pouchitis disease activity index: a simplified approach to the diagnosis of pouchitis. Dis Colon Rectum. 2003;46:748-753. doi:10.1007/s10350-004-6652-8

50. Samaan MA, Shen B, Mosli MH, et al. Reliability among central readers in the evaluation of endoscopic disease activity in pouchitis. Gastrointest Endosc. 2018;88:360-369. doi:10.1016/j. gie.2018.04.2330

51. Zhu H, Wu XR, Queener E, Kiran RP, Remzi FH, Shen B. Clinical value of surveillance pouchoscopy in asymptomatic ileal pouch patients with underlying inflammatory bowel disease. Surg Endosc. 2013;27:4325-4332. doi:10.1007/s00464013-3054-9

52. Kayal M, Plietz M, Radcliffe M, et al. Endoscopic Activity In Asymptomatic Patients With An Ileal Pouch Is Associated With An Increased Risk of Pouchitis. Aliment Pharmacol Ther. 2019;50:1189-1194. doi:10.1111/apt.15505

53. Samaan MA, de Jong D, Sahami S, et al. Incidence and severity of prepouch ileitis: a distinct disease entity or a manifestation of refractory pouchitis? Inflamm Bowel Dis. 2016;22:662-668. doi:10.1097/ MIB.0000000000000593

54. Rottoli M, Vallicelli C, Bigonzi E, et al. Prepouch ileitis after ileal pouch-anal anastomosis: patterns of presentation and risk factors for failure of treatment. J Crohns Colitis. 2018;12:273-279. doi:10.1093/ ecco-jcc/jjx140

55. Setti Carraro PG, Talbot IC, Nicholls JR. Patterns of distribution of endoscopic and histological changes in the ileal reservoir after restorative proctocolectomy for ulcerative colitis. A long-term follow-up study. Int $J$ Colorectal Dis. 1998;13:103-107. doi:10.1007/s003840050144

56. Tulchinsky H, Hawley PR, Nicholls J. Long-term failure after restorative proctocolectomy for ulcerative colitis. Ann. 2003;238:229-234. doi:10.1097/01.sla.0000082121.84763.4c

57. Belliveau P, Trudel J, Vasilevsky CA, Stein B, Gordon PH. Ileoanal anastomosis with reservoirs: complications and long-term results. Can J Surg. 1999;42:345-352.

58. Hurst RD, Chung TP, Rubin M, Michelassi F. Implications of acute pouchitis on the long-term functional results after restorative proctocolectomy. Inflamm Bowel Dis. 1998;4:280-284. doi:10.1002/ ibd. 3780040405

59. Shen B, Achkar JP, Lashner BA, et al. A randomized trial of ciprofloxacin and metronidazole in treating acute pouchitis. Inflamm Bowel Dis. 2001;7:301-305. doi:10.1097/00054725-20011100000004
60. Sambuelli A, Boerr L, Negreira S. Budesonide enema in pouchitis. A double-blind, double-dummy, controlledtrial. Aliment Pharmacol Ther. 2002;16:27-34. doi:10.1046/j.1365-2036.2002.01139.x

61. Isaacs KL, Sandler RS, Abreu M, et al. Rifaximin for the treatment of active pouchitis: a randomized, double-blind, placebo-controlled pilot study. Inflamm Bowel Dis. 2007;13:1250. doi:10.1002/ibd.20187

62. Kuisma J, Mentuls S, Jarvinen H, Kahri A, Saxelin M, Farkkila M. Effect of lactobacillus rhamnosus GG on ileal pouch inflammation and microbial flora. Aliment Pharmacol Ther. 2003;17:509-515. doi:10.1046/j.1365-2036.2003.01465.x

63. Gionchetti P, Rizzello F, Morselli C, et al. High-dose probiotics for the treatment of active pouchitis. Dis Colon Rectum. 2007;50:2075-2084. doi:10.1007/s10350-007-9068-4

64. Gionchetti P, Rizzello F, Helwig U, et al. Prophylaxis of pouchitis onset with probiotic therapy: a double-blind placebo controlled trial. Gastroenterology. 2003;124:1202-1209. doi:10.1016/s0016-5085(03) 00171-9

65. Gosselink MP, Schouten WR, van Lieshout LMC, Hop WCJ, Laman JD, Ruseler-van Embden JGH. Delay of the first onset of pouchitis by oral intake of the probiotic strain Lactobacillus rhamnosus GG. Dis Colon Rectum. 2004;47:876-884. doi:10.1007/s10350004-0525-z

66. Ha CY, Bauer JJ, Lazarev M, et al. Early institution of tinidazole may prevent pouchitis following ileal pouch-anal anastomosis (IPAA) surgery in ulcerative colitis (UC) patients. Gastroenterology. 2010;138(5 Suppl 1):S69. doi:10.1016/S0016-5085(10)60314-9

67. Gionchetti P, Rizzello F, Venturi A, et al. Oral bacteriotherapy as maintenance treatment in patients with chronic pouchitis: a double-blind, placebo-controlled trial. Gastroenterology. 2000;119:305-309. doi:10.1053/gast.2000.9370

68. Mimura T, Rizzello F, Helwig U, et al. Once daily high dose probiotic therapy for maintaining remission in recurrent or refractory pouchitis. Gut. 2004;53:108-114. doi:10.1136/gut.53.1.108

69. Segal JP, Poo SX, McLaughlin SD, Faiz OD, Clark SK, Hart AL. Long term follow-up of the use of maintenance antibiotic therapy for chronic antibiotic-dependent pouchitis. Frontline Gastroenterol. 2018;9:154-158. doi:10.1136/flgastro-2017-100913

70. Lavryk OA, Stocchi L, Shawki S, et al. Redo IPAA After a Failed Pouch In Patients With Crohn's Disease: is It Worth Trying? Dis Colon Rectum. 2020;63:823-830. doi:10.1097/ DCR.0000000000001644

71. Gionchetti P, Rizzello F, Venturi A, et al. Antibiotic combination therapy in patients with chronic treatment-resistant pouchitis. Aliment Pharmacol Ther. 1999;13:713-718. doi:10.1046/j.13652036.1999.00553.x

72. Abdelrazeq AS, Kelly SM, Lund JN, Leveson SH. Rifaximin-ciprofloxacin combination therapy is effective in chronic active refractory pouchitis. Colorectal Dis. 2005;7:182-186. doi:10.1111/j.14631318.2004.00746.x

73. Mimura T, Rizzello F, Helwig U, et al. Four-week open-label trial of metronidazole and ciprofloxacin for the treatment of recurrent or refractory pouchitis. Aliment Pharmacol Ther. 2002;16:909-917. doi:10.1046/j.1365-2036.2002.01203.x

74. Shen B, Fazio VW, Remzi FH, et al. Combined ciprofloxacin and tinidazole in the treatment of chronic refractory pouchitis. Dis Colon Rectum. 2007;50:498-508. doi:10.1007/s10350-006-0828-3

75. Gionchetti P, Rizzello F, Poggioli G, et al. Oral budesonide in the treatment of chronic refractory pouchitis. Aliment Pharmacol Ther. 2007;25:1231-1236. doi:10.1111/j.1365-2036.2007.03306.x

76. Gionchetti P, Calabrese C, Calafiore A, et al. Oral beclomethasone dipropionate in chronic refractory pouchitis. J Crohn's Colitis. 2014;8:649-653. doi:10.1016/j.crohns.2013.12.001

77. Uchino M, Ikeuchi H, Matsuoka H, et al. Topical tacrolimus therapy for antibiotic-refractory pouchitis. Dis Colon Rectum. 2013;56:1166-1173. doi:10.1097/DCR.0b013e31829ebd83 
78. Huguet M, Pereira B, Goutte M, Goutorbe F, Dubois A, Bommelaer G. Systematic review with meta-analysis: anti-TNF therapy inrefractory pouchitis and Crohn's disease-like complications of the pouch after ileal pouch-anal anastomosis following colectomy for ulcerative colitis. Inflamm Bowel Dis. 2018;24:261-268. doi:10.1093/ $\mathrm{ibd} / \mathrm{izx} 049$

79. Gregory M, Weaver KN, Hoversten P, et al. Efficacy of Vedolizumab for Refractory Pouchitis of the Ileo-anal Pouch: results From a Multicenter US Cohort. Inflamm Bowel Dis. 2019;25:1569-1576. doi:10.1093/ibd/izz030
80. Singh A, Khan F, Lopez R, Shen B, Philpott J. Vedolizumab for chronic antibiotic-refractory pouchitis. Gastroenterol Rep. 2019;7:121-126. doi:10.1093/gastro/goz001

81. Ribaldone DG, Pellicano R, Saracco GM, Morino M, Astegiano M. Vedolizumab for treatment of chronic refractory pouchitis: a systematic review with pool analysis. Rev Esp Enferm Dig. 2020;112:59-63. doi:10.17235/reed.2019.6336/2019

82. Ollech JE, Rubin DT, Glick L, et al. Ustekinumab Is Effective for the Treatment of Chronic Antibiotic-Refractory Pouchitis. Dig Dis Sci. 2019;64:3596-3601. doi:10.1007/s10620-019-05697-1

\section{Publish your work in this journal}

The International Journal of General Medicine is an international, peer-reviewed open-access journal that focuses on general and internal medicine, pathogenesis, epidemiology, diagnosis, monitoring and treatment protocols. The journal is characterized by the rapid reporting of reviews, original research and clinical studies across all disease areas. The manuscript management system is completely online and includes a very quick and fair peer-review system, which is all easy to use. Visit http://www.dovepress.com/ testimonials.php to read real quotes from published authors.

Submit your manuscript here: https://www.dovepress.com/international-journal-of-general-medicine-journal 